\section{SOBRENDEUDAMIENTO, EJECUCIONES HIPOTECARIAS Y CUESTIONAMIENTO DE LA LEGITIMIDAD DE LAS DEUDAS}

\author{
Irene Sabaté Muriel \\ Universitat de Barcelona \\ http://orcid.org/0000-0001-8470-0765 \\ sabate.irene@gmail.com
}

\section{OVER-INDEBTEDNESS, HOME REPOSSESSIONS AND THE CHALLENGING OF DEBT LEGITIMACY}

Copyright: (C) 2019 CSIC. Este es un artículo de acceso abierto distribuido bajo los términos de la licencia de uso y distribución Creative Commons Reconocimiento 4.0 Internacional (CC BY 4.0).
Cómo citar este artículo/Citation: Sabaté Muriel, I. (2019). Sobrendeudamiento, ejecuciones hipotecarias y cuestionamiento de la legitimidad de las deudas. Arbor, 195 (793): a516. https:// doi.org/10.3989/arbor.2019.793n3004

Recibido: 12 febrero 2016. Aceptado: 31 marzo 2016.

RESUMEN: Como consecuencia de la crisis económica, inmobiliaria y financiera experimentada en España en los últimos años, muchos deudores hipotecarios no pueden hacer frente a sus cuotas y corren el riesgo de perder sus viviendas, en ocasiones conservando una deuda imposible de afrontar. El sobrendeudamiento y la morosidad hipotecaria abocan así a ciertas economías domésticas a situaciones insostenibles que pueden llevar a una reordenación de los gastos y necesidades, entre los que las cuotas hipotecarias dejan de tener prioridad. La legitimación de la condición de moroso que puede observarse en esos casos es un fenómeno con importantes implicaciones antropológicas, en la medida en que constituye un cuestionamiento de la obligación de devolver el préstamo. Desde el punto de vista de los deudores y de quienes les brindan apoyo, caer en el impago, lejos de constituir una transgresión moralmente reprobable, puede entenderse como un acto de responsabilidad que tiende al sostenimiento de la vida.

PALABRAS CLAVE: Hipotecas; deuda y crédito; vivienda; ejecuciones hipotecarias; desahucios; Barcelona.
ABSTRACT: As a consequence of the economic, financial and real-estate crisis experienced in Spain during recent years, many mortgage debtors cannot meet their repayments and are at risk of remaining seriously indebted after the eviction. Overindebtedness and mortgage default lead domestic economies to unsustainable situations that are forcing people to reorganize needs and expenses, and to reconsider the priority of mortgage repayments. The legitimization of the condition of the defaulting mortgagor that can be observed in such cases has important implications in anthropological terms, as it entails a challenge to the obligation to repay. From the viewpoint of debtors, and of those who support them, entering default, far from being a reprehensible action in moral terms, can be understood as an act of responsibility aimed at sustaining life.

KEYWORDS: Mortgages; debt and credit; housing; home repossessions; evictions; Barcelona. 


\section{LA INSOSTENIBILIDAD DE LA DEUDA HIPOTECARIA}

En 1996, cuando Esmeralda (véase tabla 1) y su marido ingresaban entre 3.000 y 4.000 euros mensuales por sus respectivos trabajos en la construcción y en una peluquería propia, una cuota hipotecaria de algo menos de 1.000 euros resultaba perfectamente asumible. Fue así como se decidieron a comprar su vivienda actual en l'Hospitalet de Llobregat y luego, hacia 2004, ampliaron la hipoteca para adquirir también un apartamento en la costa de Castellón. Esta segunda compra, más que a una decisión aventurada, obedecía a una previsión de futuro por parte de la pareja: autónomos ambos, pensaron que la inversión en una segunda residencia serviría para complementar sus futuras pensiones, previsiblemente bajas. No obstante, en 2014, tras dieciocho años cumpliendo con sus obligaciones financieras, los problemas de salud, sumados al desempleo de larga duración, obligaron a Esmeralda y a su marido a dejar de pagar las cuotas. Hoy subsisten con una pensión de 408 euros, con la que mantienen también a su hijo menor, y se encuentran en riesgo de perder los dos inmuebles ante Bankia, con quien tratan de negociar una salida que les permita conservar un lugar donde habitar de manera asequible y estable.

El caso de Esmeralda ilustra las circunstancias en que se encuentran los deudores españoles que, años después de contraer la deuda hipotecaria, se ven incapaces de satisfacer las cuotas. En la mayor parte de los casos, son víctimas de circunstancias estructurales (véase Sales i Campos, 2014, p. 11) incontrolables o difícilmente pronosticables, como la pérdida del trabajo o el deterioro de las condiciones laborales, la desvalorización de los inmuebles, el aumento de los tipos de interés, los problemas de salud, las rupturas de pareja, etc. Así, mientras que el nivel de ingresos y la capacidad de movilizar recursos por otras vías -como las redes de apoyo informales o la asistencia social- disminuyen en los largos años de la crisis económica (Lorenzo Gilsanz, 2014, p. 212), las obligaciones financieras se mantienen o se endurecen. A lo largo de este tiempo muchas familias han visto empeorar drásticamente la relación entre sus ingresos y sus gastos ${ }^{1}$, hasta el punto de verse ante la amenaza de perder la vivienda (Carbonero Muñoz y Ruiz Vega, 2016, p. 52; Cabrera, 2004, p. 13). Como factores de ese empeoramiento se encuentra el aumento de los índices que regulan el pago de intereses, el efecto de las cláusulas suelo, así como las refinanciaciones que, si bien suponen un alivio momentáneo, provo- can a la postre un aumento de las cuotas y de la deuda total por la que se ha de responder, tal y como nos explicaban un abogado del departamento de contenciosos de uno de los principales bancos:

"Muchas de las refinanciaciones que se han hecho a lo largo de estos tres últimos años [2009-2012] están entrando otra vez en mora y se están ejecutando. Porcentajes no sé... pero más del cincuenta... seguro. Se ha estado postergando el problema [...]. O se ha agravado, porque lo que se hace es que con la carencia estás generando más intereses, y el día de mañana te das cuenta de que tienes más deuda que al principio. Quizá la intención inicial de hacer la refinanciación era cuando no se creía que esta situación iba a durar tanto. Que la economía se reactivaría en dos... tres años y por tanto podrían hacer frente a la nueva cuota cuando venciera la carencia. Cosa que no se está dando. Entonces provocas que entren otra vez...".

Asimismo, las situaciones de morosidad suponen una amenaza tanto para los propios deudores como, de haberlos, para sus avaladores, dado que todos ellos responden ante el acreedor con su patrimonio e ingresos.

Esta suma de circunstancias aboca a las economías domésticas a situaciones insostenibles, en un proceso multifactorial que resulta pertinente analizar en términos antropológicos. Así pues, ¿qué implicaciones tiene la situación de morosidad hipotecaria para sus protagonistas, en términos de atribución y asunción de responsabilidades, tanto en términos retrospectivos y morales -cuando se identifican los factores y las prácticas que han llevado a la actual situación- como en sus proyecciones de futuro -al intentar trazar estrategias que permitan salir adelante? ¿Cómo evolucionan estas atribuciones y asunciones de responsabilidad, y en qué medida lo hacen en relación con cambios en las prioridades de la economía doméstica a lo largo del proceso de ejecución hipotecaria?

Trataremos de dar respuesta a estas preguntas de investigación mediante una aproximación cualitativa a los casos concretos de deudores que describen -en primera persona y desde la óptica de la economía doméstica- sus experiencias y percepciones ante la amenaza de la ejecución hipotecaria. Lo veremos sobre la base de una serie de datos etnográficos recogidos en el área metropolitana de Barcelona entre los años 2012 y 2015, a través de entrevistas semidirigidas y de sesiones de observación durante asambleas y movilizaciones de la Plataforma de Afectados por la Hipoteca (PAH) (los datos de los informantes se recogen en la tabla 1 ). 
Tabla 1. Datos de los informantes y situación de la deuda hipotecaria

\begin{tabular}{|c|l|c|c|l|l|l|}
\hline Código & $\begin{array}{l}\text { Nombre o } \\
\text { pseudónimo }\end{array}$ & Género & Edad & Origen & \multicolumn{1}{|c|}{ Ocupación } & \multicolumn{1}{|c|}{ Situación hipoteca } \\
\hline 1 & Esmeralda & F & 49 & España & Peluquera con incapacidad & En mora, aún en el piso. \\
\hline 2 & X & M & n. c. & España & Abogado de un banco & (no especificada) \\
\hline 3 & Nelson & M & 55 & Ecuador & $\begin{array}{l}\text { Trabajador de la } \\
\text { construcción desempleado }\end{array}$ & Ejecutado, de alquiler. \\
\hline 4 & Vanessa & F & 53 & España & $\begin{array}{l}\text { Guardia de seguridad } \\
\text { desempleada }\end{array}$ & $\begin{array}{l}\text { Ejecutada, en casa de sus } \\
\text { padres. }\end{array}$ \\
\hline 5 & Junior & M & 25 & Ecuador & Instalador de telefonía & Ejecutado, de alquiler. \\
\hline 6 & Salvador & M & 41 & España & Guardia de seguridad & En mora, aún en el piso. \\
\hline 7 & $\begin{array}{l}\text { Diego } \\
\text { Gutiérrez }\end{array}$ & M & n. c. & España & Juez & (no especificada) \\
\hline 9 & Maite & F & 35 & España & Cajera de supermercado & En mora, aún en el piso. \\
\hline 10 & Esteban & M & 54 & España & Electricista con incapacidad & En mora, aún en el piso. \\
\hline 11 & Hernán & M & 39 & Argentina & $\begin{array}{l}\text { Ex empresario de la } \\
\text { construcción }\end{array}$ & $\begin{array}{l}\text { Ejecutado, ocupando una } \\
\text { vivienda. }\end{array}$ \\
\hline 12 & Juan & M & 42 & España & $\begin{array}{l}\text { Trabajador de la } \\
\text { construcción desempleado }\end{array}$ & En mora, aún en el piso. \\
\hline 13 & Ramón & M & 67 & España & Ex empresario & Ejecutado, de alquiler. \\
\hline
\end{tabular}

Fuente: Elaboración propia.

\section{Significados cambiantes}

En situaciones de distrés financiero (Sabaté, 2018) como las que acabamos de describir, se producen profundos cambios en el plano de los significados. Así, por ejemplo, la representación del crédito como algo positivo, como una oportunidad o una suerte para el deudor, es sustituida por una nueva imagen, la de la deuda como algo negativo, una carga o una condena que obstaculiza la obtención del sustento y niega oportunidades de futuro (Gregory, 2012). En línea con esto, Nelson, un deudor de origen ecuatoriano que compró una vivienda en 2004 , describe cómo, en el momento de firmar la hipoteca con un mediador inmobiliario y mediante una estrategia de avales cruzados con un compatriota, su percepción era que todos los actores, incluido el banco, le estaban haciendo un favor. Hoy, tras una dura lucha que le ha permitido obtener la dación en pago, su percepción ha cambiado radicalmente: siente que fue víctima de un engaño. Por su parte, Vanessa, una barcelonesa que ha perdido su piso y ve peligrar el de sus padres por haberla avalado, describe un proceso muy similar:
"Pensé: «estoy pagando 800 de alquiler... Por un poquito más -ganaba más de 2.000 euros- pues me meto en un piso. Al fin y al cabo, será para mí y en un futuro para mis hijas». Y ahí fue donde digo que firmé mi sentencia de muerte, entre comillas" (Vanessa).

Un razonamiento similar lleva a Esmeralda a afirmar:

"Tengo dos pisos... Bueno, dos pisos no, dos problemas. Los pisos son más del banco que míos" (Esmeralda).

En este proceso puede identificarse también una transformación drástica de las subjetividades y representaciones sociales de los distintos actores implicados en el endeudamiento hipotecario. Las entidades bancarias, que en tiempos de bonanza eran vistas como benefactoras de la sociedad y propiciadoras de la actividad económica, pasan a ser objeto de crítica y son representadas como usureras y depredadoras por quienes sufren los rigores de las ejecuciones hipotecarias, así como por quienes empatizan con ellas.

Por su parte, los empleados de banca, en otro tiempo comúnmente vistos como proveedores casi desinteresa- 
dos de asesoramiento a unos clientes que tenían depositada su confianza en ellos, son hoy identificados con los objetivos del negocio bancario, y acusados de ser beneficiarios y cómplices de lo que amplios sectores sociales consideran una estafa a gran escala. Así, cuando Junior, hijo de Nelson, acudió por primera vez a una asamblea de la PAH en busca de orientación para enfrentarse con el problema hipotecario, sus palabras expresaban cierta comprensión con la actuación de los empleados de banca que habían dado pie a la firma de su hipoteca. Sin embargo, a medida que pasaban las semanas, el discurso de Junior al respecto mutó radicalmente, dando paso a una crítica feroz de la mala fe con que aquellos profesionales se habían lucrado a costa de su familia.

La erosión y la ruptura de las relaciones entre empleados y clientes han facilitado este juicio moral negativo acerca del papel de la banca en general y de los empleados bancarios en particular. Factores como las fusiones entre entidades bancarias, la reducción de sus plantillas, la supresión o el traslado de oficinas, la elevación de los casos de morosidad a departamentos internos de recuperaciones o impagos, así como estrategias deliberadas de subcontratación de los servicios de recobro que utilizan mayoritariamente la vía telefónica y evitan todo contacto personal con los deudores han contribuido a una despersonalización de la relación entre acreedores y deudores.

Por último, también la representación social de los deudores ha sufrido un proceso de cambio: de ser percibidos -y auto percibirse- como inversores o emprendedores que buscaban su bienestar material haciendo un uso audaz de los resortes del mercado inmobiliario, pasan hoy a ser tachados -y a tacharse a sí mismos en muchos casos- de irresponsables o ambiciosos en exceso, y en consecuencia son culpabilizados de su situación (Cabrera, 2004, p. 14). De llegar a la ejecución, aparecen como protagonistas de un proyecto fracasado. Así lo expresa Salvador, que se expone a la ejecución de su piso y el de sus suegros:

"He fallado a una parte de mi familia. No he podido hacer frente a todo. Para mí eso ya representa algo bastante duro de asumir" (Salvador).

\section{Obligaciones ineludibles}

Junto con estas transformaciones en el ámbito de los significados, resulta también relevante analizar el contraste entre la rigidez de la relación hipotecaria y la fluidez del contexto social y económico en el que esta aparece enmarcada. El carácter contractual de este vínculo hace de él algo inflexible y deja en prin- cipio poco margen para la negociación, dado que los términos del contrato solo podrán ser modificados si accede a ello la parte más fuerte, la entidad bancaria. Esto remite, tal y como señala el notario Ángel Serrano de Nicolás (2015, p. 169), al hecho de que, lejos de negociarse individualmente cláusula a cláusula, se trata de contratos en masa y de adhesión, "pues todos se hacen conforme a minuta procedente de la Entidad acreedora y de acuerdo con sus condiciones generales de contratación, que [...] se aceptan o no íntegramente, tal y cual está redactada y predispuesta dicha minuta".

En el ámbito judicial, esta rigidez y predisposición de los contratos, unida a la implacabilidad de la legislación, da pie a lo que uno de nuestros informantes, el juez de Lleida Diego Gutiérrez, nos describía como sigue:

"La ejecución hipotecaria es un procedimiento estándar, muy tasado y rígido. Cuestiones muy formales. Los deudores hipotecarios tienen unas causas muy limitadas para oponerse, para defenderse del procedimiento, porque estrictamente la ejecución implica que o has dejado de pagar o has pagado. Una cuota hipotecaria con la que hay que cumplir... Si no se cumple, el procedimiento es sencillo: se subasta el inmueble, el banco o un tercero se lo adjudica y, si sobra algo de dinero, te lo quedas".

Esto no impide, no obstante, que en los últimos años se hayan producido algunos esfuerzos para forzar sentencias favorables a los deudores. Ejemplo de ello ha sido el uso hábil de la jurisprudencia por parte de algunos jueces que, pese a estar comprometidos con el principio de la legalidad, han visto cierto margen de movimiento para tratar de humanizar la aplicación estricta de la legislación y de las cláusulas contractuales. Como elemento común a estas prácticas identificamos la toma en consideración del caso particular, de las circunstancias que han llevado a un determinado grupo doméstico a la morosidad y la insolvencia. Con ello se consigue matizar el concepto de deuda imperante bajo el capitalismo financiero, que implica una estipulación rígida de los plazos y condiciones de la devolución (Guyer, 2012), para adaptarlo a una situación de excepcionalidad causada por la crisis económica y sus previsibles consecuencias en términos de fragilización social (Moreno Márquez y Aierdi Urraza, 2015, p. 4; Sales i Campos, Diagnosis 2013). Una posibilidad en este sentido pasaría por la neutralización de la fuerza del contrato con el argumento de que las circunstancias en que este fue suscrito se han visto radicalmente 
transformadas ${ }^{2}$. Junto a esta vía, que es objeto de controversia entre los juristas, aparece otra basada en el reajuste de las obligaciones del deudor con arreglo a sus posibilidades actuales, de forma que la sostenibilidad de la deuda sea preservada. Esto se ha visto finalmente contemplado en la legislación de segunda oportunidad promulgada en $2015^{3}$. Ciertas modificaciones de las condiciones de pago de las hipotecas se vienen produciendo a iniciativa de los propios acreedores (Stout, 2015, 30 de marzo), dado que tal "flexibilización" puede constituir en sí misma una oportunidad de beneficio. Así ha ocurrido, por ejemplo, cuando los empleados bancarios animan a los deudores a ingresar las cuotas incompletas cuando eran incapaces de pagarlas íntegramente. Tales pagos incompletos no contribuyen a saldar la deuda ni evitan que se desencadene la ejecución si así lo decide el banco pero, en el plano de las normas sociales y de los juicios morales, pueden ser vistas, tanto por los deudores como por los representantes de la entidad acreedora, como muestras de buena fe y de la voluntad de reanudar los pagos completos cuando la economía familiar se recupere. Junto a esto podemos situar también las ya mencionadas refinanciaciones que, desde el punto de vista de los bancos, han constituido la principal estrategia para invisibilizar la morosidad o posponer su manifestación, al tiempo que funcionan como una fuente de lucro al permitir que se disparen los intereses de demora, como parece estar ocurriendo en el caso de Salvador:

"No tengo una demanda judicial todavía por eso. Quieren que alcance ese nivel donde yo ya no pueda responder [con el valor del piso hipotecado y el del aval]" (Salvador).

A esta lógica obedecen también las fuertes presiones recibidas por muchos deudores con dificultades para pagar, o que se encuentran ya en mora, para que acepten distintos tipos de refinanciaciones. Maite identifica en estos términos los beneficios que el banco esperaba extraer si ella y su marido aceptaban una segunda carencia:

“Dejamos de pagar en septiembre de 2009, después de ofrecernos la carencia, que nos iban a engañar. Ya nos pusimos en contacto con la PAH, no veíamos claro lo que nos estaban ofreciendo, tener que volver a pagar el notario, otra vez 3.000 euros, más el tasador... En total subía a 6.000 o 8.000 euros... que «tranquila, que te los metemos en la hipoteca». «iPero si no tengo dinero!» [...] Yo le pedí una minuta de la carencia que ofrecían. Tardaron en hacerla. Y después me veo en la libreta [de la cuenta bancaria] menos... Todo era menos, ellos iban cobrando y no había ni un duro... menos 50 o 35 euros de gastos de gestoría. ¿Pido el papel y me lo cobran? ¿Qué es esto?" (Maite).

Deudores como la propia Maite interpretan a posteriori como una equivocación, fruto de su desorientación y desconocimiento iniciales, haber aceptado una refinanciación al surgir los primeros problemas económicos. Para los deudores en mora, la posibilidad aparece como una tabla de salvación provisional que al mismo tiempo sirve a los intereses del banco. Así lo explica Esmeralda:

"Cuando ves que no puedes, te proponen las refinanciaciones y eso es lo peor. Claro, te lo presentan como solución: «en vez de pagar 1.200 voy a pagar $500 \ldots$ qué bien, durante dos años». Piensas que en dos años la cosa va a ir mejor. Pero el problema es que durante ese tiempo no estás pagando hipoteca, solo pagas intereses. Y al hacerte la refinanciación también tiene unos gastos. A lo mejor pasas de deber 120 a deber 150. Y has estado dos años tirando el dinero. Todo se hace una bola. De deber 100.000 euros, igual acabas debiendo 300.000. Y la deuda triplica el valor del piso, esa es otra" (Esmeralda).

En estos relatos emerge con fuerza la importancia del factor temporal: las refinanciaciones se ven como alivios momentáneos en unas circunstancias en que resulta imposible planificar la economía doméstica a medio plazo. En efecto, una refinanciación hipotecaria que permita una disminución temporal de las cuotas podría constituir una solución a situaciones pasajeras, pero ¿resultan eficaces en el contexto de una crisis tan prolongada, que implica una total falta de esperanzas para grandes sectores sociales? En este sentido, otras propuestas de solución, como la dación en pago o los procedimientos de insolvencia, representan una ruptura, en la medida en que requieren una nueva conceptualización de la normalidad y la anormalidad, en un momento en que la inestabilidad y la precariedad económicas resultan cotidianas para muchos grupos domésticos.

La exigencia de cumplir con las obligaciones impuestas por los contratos de préstamo hipotecario entra en colisión con la reivindicación de tener garantizados unos mínimos estándares de vida, como concordaría con los ideales de estabilidad, seguridad o tranquilidad que, como principios de una economía moral (Sabaté, 2016a; Scott, 1976), aparecen ampliamente compartidos por las mayorías sociales ${ }^{4}$. Esto no entraría en contradicción con la asunción de unas respon- 
sabilidades y obligaciones derivadas de la condición de deudores ni tampoco llegaría a cuestionar la obligación de devolver (Graeber, 2011). Lejos de ello, se estaría meramente matizando tal obligación, al ajustarla o condicionarla a las posibilidades materiales y particulares de hacerlo en los términos estipulados. Así se trasluce en las palabras de Salvador:

"Dame facilidades para que yo pueda pagar y yo me comprometo. Tengo trabajo, puedo pagarte 300, 350, 400 ... pero deja que mi familia se mantenga segura, estable, bien. No me intentes echar a la calle ni abusar de mí" (Salvador).

En las narraciones de los deudores, la insostenibilidad en el tiempo de la deuda hipotecaria aparece, junto con la irregularidad y precariedad del ingreso, como la principal amenaza para el sustento. Esmeralda lo expresa en términos de su incapacidad para tomar decisiones económicas que impliquen cierta perspectiva temporal:

"Entonces no puedes hacer cuentas... decir: «tiro por aquí o por allí». No puedes tirar por ningún sitio. Le das mil vueltas y siempre falta lo principal, que es el dinero. $Y$ las perspectivas de que la cosa vaya un poquito a mejor" (Esmeralda).

La dificultad de escapar a la espiral del sobrendeudamiento se debe a que este no solo tiene una dimensión económica sino también unas implicaciones morales que reducen aún más las posibles salidas.

En tales circunstancias ¿es la decisión de dejar de pagar las cuotas hipotecarias una salida justificable en términos tanto económicos como morales? Antes de tratar de abordar esta cuestión, veamos cuáles son las implicaciones de alcanzar la condición de moroso hipotecario.

\section{LAS IMPLICACIONES DEL IMPAGO}

Cuando los deudores hipotecarios entran en mora con solo tres recibos impagados, el banco tiene derecho a reclamar de golpe la deuda total, que en origen iba a pagarse en los próximos veinte o treinta años. Si, como es común, el deudor no está en situación de responder ante ello, se abre la posibilidad de la ejecución hipotecaria. La legitimidad de esta estipulación legal está siendo cuestionada incluso por representantes de la judicatura que abogan por un cambio en el marco legal. En todo caso, el hecho es que los deudores que ven inminente el momento de dejar de pagar las cuotas se ven en la situación de tener que renunciar a sus proyectos vitales, fuerte- mente centrados en la vivienda de propiedad. Esta tendía a entenderse como la concreción material del hogar, como el elemento principal del arraigo, y su consecución era un hito en el ciclo del grupo doméstico. La vivienda constituía así una fuente de bienestar material en el presente al tiempo que aportaba una garantía de seguridad de cara al futuro. Todas estas connotaciones aparecen contenidas en las palabras de Sonia, a quien, como a otras víctimas de exclusión residencial (Laparra Navarro y Pérez Eransus, 2012, p. 23, p. 125; Lorenzo Gilsanz, 2014; Moreno Márquez y Aierdi Urraza, 2015, p. 8; Sales i Campos, Diagnosis 2013), la amenaza de la ejecución y las dificultades económicas han deparado una ruptura de pareja y el regreso a casa de sus padres mientras batalla por la dación en pago:

"Estoy luchando para perder, eso es lo malo. Claro que quiero deshacerme del piso ya, pero no olvidemos que no solo se quedan el piso, se quedan el piso y las ilusiones de una vida, y eso no tiene precio. Y además quieren ponerle un precio para seguir ganando, eso es lo que llevas mal. No porque te deshaces del muerto, porque realmente es un muerto, es por el hecho de que no solo se quedan con cuatro paredes, se quedan con mucho más, se quedan con todas las ilusiones, las esperanzas de una vida... se quedan con muchísimas cosas, y hasta que no lo digieres, pues..." (Sonia)

La destrucción de los proyectos y expectativas aparece también en el discurso de Esmeralda:

"Se están destruyendo familias por esto. Porque no solamente es que te quiten el piso, es que te quitan las ilusiones. No puedes pensar ni tener esperanza" (Esmeralda).

Y a las ilusiones frustradas se suma la subversión de la secuencia de acontecimientos comúnmente esperada en el ciclo doméstico o vital, las trayectorias de ascenso social o los proyectos migratorios, poniendo a los deudores ante el riesgo de ver cronificada su situación de falta de oportunidades (Moreno Márquez y Aierdi Urraza, 2015, p. 10). Nelson expresaba esa triple anomalía cuando narraba cómo, al obtener la dación en pago y tener que alojarse su familia en habitaciones realquiladas, había vuelto a sentirse "como un tierno", como cuando, más de una década atrás, empezó a abrirse camino en Barcelona buscando trabajo y alojamiento, antes de la reagrupación familiar.

Son muchos los deudores que, al referirse a la pérdida de la vivienda, la valoran como un fracaso y reconocen en ella un error de cálculo cometido en el 
pasado, fruto de una percepción excesivamente optimista de la realidad. El empleo, a menudo en sectores hiperflexibles como la construcción o los servicios (Cabrera Cabrera, 2009, p. 5), era menos estable de lo que imaginaban, el nivel de ingresos más contingente, y no han sido capaces de mantener el nivel de vida durante las dos o tres décadas abarcadas por el plazo de devolución. Esteban, a quien un problema de salud ha abocado al desempleo y se encuentra hoy con una deuda equivalente a la contraída hace nueve años, habla de cómo toda la familia, incluidas sus hijas ya adultas, ha aprendido la lección:

"Hay que aprender de la situación. Que no hay que meterse en cosas. Hay que calcular mucho. Que las ilusiones son una cosa... y luego vienen las obligaciones" (Esteban).

Esto no impide, no obstante, que los mismos deudores atribuyan responsabilidad también a otros actores, en especial a los bancos y a las autoridades públicas. Así lo denuncia el mismo Esteban:

"Todos sabemos que nosotros somos una pequeña parte de lo que ha pasado. Los creadores de todo han sido ellos [la banca] y el Gobierno" (Esteban).

O en palabras de Esmeralda:

"Si hicimos mal las cuentas o lo que sea, también ellos las hicieron mal" (Esmeralda).

Y de esta constatación surgen denuncias acerca de la indefensión de los deudores con dificultades y la reclamación del derecho a recibir asistencia estatal. Así lo afirma la propia Esmeralda:

“¿A ellos no los han rescatado? Pues que nos rescaten a nosotros. Porque Bankia ha sido rescatada con muchísimo dinero. Nosotros también tenemos derecho a que nos rescaten" (Esmeralda).

Por su parte, Hernán, que perdió su vivienda tras la quiebra de su empresa, critica la connivencia entre los políticos y la banca, así como la existencia de viviendas vacías en manos de esta última:

"Lo que no puede ser es que haya tanta gente durmiendo en la calle y siendo desahuciada y tantos pisos vacíos de los bancos y tantos políticos enriqueciéndose" (Hernán).

En ocasiones, los propios deudores formulan propuestas concretas acerca de cómo el Estado debería abordar la cuestión. Salvador proponía lo siguiente:

"Tú coges, creas un fondo ICO, haces un estudio de las morosidades, y la gente se puede acoger a ello, liquidas la deuda con el banco, y la gente tiene la deuda con el Estado" (Salvador).

Pero más allá de la atribución de responsabilidades y de las propuestas de solución, en las experiencias de los deudores se revela cómo la fuerza de la norma que obliga a devolver las deudas (Graeber, 2011) dificulta enormemente el paso de dejar de pagar. Esto se debe a que el moroso es visto, en mayor o menor medida y por unos u otros actores -desde él mismo hasta la opinión pública en general-, como alguien que incumple un compromiso, un contrato al que accedió de manera supuestamente libre. A raíz de ese incumplimiento es culpado de manera individual y post facto. Es alguien que falla al banco como cliente y falla también a quienes dependen de él para obtener el sustento y acceder a la vivienda. Esto se ve en las palabras de Salvador:

"He fallado a una parte de mi familia. No he podido hacer frente a todo. Para mí eso ya representa algo bastante duro de asumir. Pero si soy capaz de hacerle frente no intentes castigarme más. Asumo mi parte de culpa" (Salvador).

La acción de "fallar", de decepcionar y de fracasar en el cumplimiento de un deber, afecta además a quienes aceptaron responder por el deudor en el plano burocrático, aportando avales o garantías, sin pensar que ese acto fuera a tener consecuencias reales. En los años de prosperidad, se avalaba en respuesta a la obligación moral implicada en los lazos sociales, pero raramente se contemplaba la eventualidad del impago. El gesto de avalar parecía quedar en el plano estrictamente burocrático. Pero hoy ese gesto constituye una amenaza real para el patrimonio de los fiadores, como hemos visto en los casos de Salvador o de Vanessa.

Ante la morosidad, los empleados de banca desempeñan un papel crucial, por ejemplo enfatizando las responsabilidades financieras de los morosos. El pago de las cuotas hipotecarias se presenta como una obligación absoluta que debe ser atendida por encima de cualquier otra consideración. En ocasiones, se recurre a argumentos basados en el estigma que cae sobre los morosos, como le ocurrió a Juan cuando comunicó al banco su incapacidad para seguir pagando:

"Me decía: «tu familia ¿sabe qué tipo de persona eres?, ¿eh? Tu obligación es pagarme»" (Juan).

Estas advertencias, amenazadoras en distintos grados, sacan partido de los miedos e incertidumbres asociados con la morosidad. Así ocurre, por ejemplo, cuando se insinúa a los deudores el peligro de perder 
la custodia de los hijos, como le ocurrió a Salvador, según sabemos por Esmeralda:

"Le dijeron lo de la niña, que los niños no pueden vivir en la calle. Imagínate cómo salió de allí" (Esmeralda).

Todas estas circunstancias contribuyen aún más a que la decisión de dejar de pagar, de producirse, constituya un punto de inflexión para los deudores, dado que implica una renuncia en un doble sentido. Por un lado, una renuncia material, puesto que se pierde tanto la vivienda como el dinero invertido en pagarla hasta el momento. Por otro lado, la renuncia simbólica a la que nos referíamos más arriba: se desvanece un proyecto de movilidad social, así como la expectativa de proporcionar algo a los hijos, tanto en términos de transmitirles los significados que acompañan al patrimonio familiar como en el sentido de poder demostrarles que la previsión y los sacrificios son justamente recompensados.

Por todo ello, dejar de pagar la hipoteca, lejos de ser una decisión fácil que pueda tomarse a la ligera como algunas voces parecen apuntar, representa un paso extraordinariamente difícil, que se cobra muchas angustias y conflictos y que, en consecuencia, tiende a retrasarse todo lo posible, pese a que no habría justificación racional para tal retraso, como describe Esmeralda:

"Hay un período en que pones la hipoteca por delante de todo y es un fallo total y absoluto porque de todas maneras vas a dejar de pagar pero piensas: "esto no va a durar, va a pasar». Yo se lo digo a mucha gente. El otro día un chico que vino llorando: «¿tú vas a poder pagar?» «No». «Pues entonces deja de pagar. No le des ni un duro más al banco, no vale la pena. Al banco le da igual que le debas 110.285 , que que le debas 110.000; le da lo mismo, y tú vas a tener para comer ese mes o para comprarles unas bambas a tus niños»" (Esmeralda).

Con la decisión tomada, la incertidumbre aumenta. ¿Cómo será la vida más allá del impago? Los deudores se enfrentan entonces a las incertidumbres derivadas de la inseguridad en la tenencia, de los ritmos a menudo arbitrarios del proceso de ejecución, así como de otras variables desconocidas o incontrolables, incluida la situación financiera del propio banco, los avatares laborales de los empleados con quienes se está negociando, los posibles cambios legislativos, la concesión o denegación de la justicia gratuita, así como determinadas dinámicas financieras que escapan al escrutinio público, como es el caso de la titulización hipotecaria (Sabaté, 2016b). Los deudores deberán ahora simultá- neamente llevar la negociación con el banco, enfrentarse a la burocracia estatal, y eventualmente deberán estar prevenidos ante los abusos de quienes pretendan extraer algún lucro de su circunstancia ${ }^{5}$. Así, para desenvolverse en la nueva situación con todos sus peligros, resultará clave disponer de asesoramiento experto y poder acceder a información, así como obtener el apoyo de su entorno o de otros agentes con quienes compartan sensibilidad o intereses.

\section{LA LEGITIMACIÓN DE LA MOROSIDAD}

Ante la total incapacidad para pagar o la perspectiva de alcanzar próximamente esa incapacidad, se desencadenan procesos que contribuyen a legitimar la morosidad en esas circunstancias específicas. Esta construcción de la morosidad legítima se opone a otro tipo de morosidad, en este caso ilegítima, que se atribuye a quienes presuntamente no sienten incomodidad en esa condición o incluso la abrazan como una estrategia que les permitiría "vivir gratis" durante algún tiempo. Los deudores entrevistados, todos ellos inmersos en algún grado en negociaciones con el banco con el objetivo de resolver su situación, ponen énfasis en diferenciarse claramente de quienes, al menos presuntamente, estarían aprovechándose de la coyuntura para salir indemnes tras un comportamiento irresponsable.

La identidad de moroso, en este sentido, se adopta con muchas barreras y matices, como vemos en las palabras de Ramón, a quien el aislamiento social y la falta de salidas han llevado a la depresión y a un intento de suicidio:

"Yo no soy moroso de profesión, yo me he vuelto insolvente por las circunstancias de la vida, ¿no? Yo simplemente si hubiera cerrado mi empresa en otra época y la hubiera podido suplir con un trabajo, pues habría podido seguir pagando, pero es que no tengo posibilidad" (Ramón).

Para Salvador, actitudes como la de Ramón o la suya propia son en realidad prevalentes entre quienes se encuentran en situación de morosidad hipotecaria:

"Nadie quiere que le regalen su casa, la gente quiere pagar" (Ramón).

También Esteban enfatiza este aspecto cuando argumenta por qué él y su esposa siguen cumpliendo con otras obligaciones financieras tras dejar de pagar la hipoteca:

"A nosotros lo que no nos gusta es dejar de pagar las cosas. La hipoteca porque es mucha cantidad, sino 
no habríamos dejado de pagarla. Es lo que siempre les decimos a ellos [los empleados del banco]. Por ejemplo, este Martínez parece como que pasamos de todo. Nos decía: «deja de pagar el ICO y pagas el alquiler [el alquiler de mercado, una cantidad superior a los ingresos familiares, que el banco les ofrecía junto con la dación]». Vaya forma de solucionar. Si no pagamos la hipoteca es porque no se puede, no porque no queramos. Y no voy a dejar de pagar cosas. No me gusta. Lo que pasa es que la hipoteca... ahí sí que ya no llego. [...]. Al menos para nosotros es una cosa muy bestia" (Esteban).

Y no falta quien, para poder seguir pagando las cuotas hipotecarias y no por ello dejar de atender otros gastos, llega a pedir otros préstamos, como ya relatábamos en el caso de Esmeralda, y como ocurre también con Vanessa:

\footnotetext{
"Tengo dos préstamos, por culpa de querer pagar la hipoteca, o por lo menos pagar los colegios, saqué un préstamo personal en el Santander" (Vanessa).
}

Estas actitudes y comportamientos están arraigados en una concepción de la buena voluntad del deudor, que hará hasta el último esfuerzo por cumplir con la obligación contraída, aun cuando eso repercuta negativamente en su bienestar o en sus posibilidades de salir adelante. La noción de moroso "de buena fe", que tiene entidad jurídica al aparecer en textos legales ${ }^{6}$ caracterizando a los deudores que pueden beneficiarse de alguna medida paliativa de su situación, aparece también con frecuencia en los discursos de los propios afectados, quienes, como ya hemos señalado y al menos durante los prolegómenos del proceso de ejecución, ponen empeño en identificarse así ante el banco. Para más tarde topar, en la mayoría de los casos, con una total indiferencia ante sus desvelos. Así lo afirma Salvador al referir cómo, antes de desencadenarse la ejecución, y por tanto antes de que el juez pueda establecer un sueldo mínimo inembargable, la entidad acreedora no tendría inconveniente en embargarle la nómina íntegramente, aun cuando eso hiciera peligrar la subsistencia de la familia:

"Ellos se cobrarían por encima de cualquier cosa la hipoteca, y si yo no tengo para comer, pues nada. Pero a ellos eso no les importa" (Salvador).

Para profundizar en estos procesos de legitimación del impago ante la amenaza de la ejecución, resulta también revelador analizar las variadas posturas adoptadas por distintos tipos de "terceros" que intervienen en las relaciones acreedor-deudor. Topamos así con distintas aproximaciones a la problemá- tica hipotecaria, tanto en lo que se refiere a las formas de intervenir en los casos como en el tipo de objetivos finales que se persiguen. Por un lado vemos a los abogados y a otros expertos que ofrecen servicios de asesoría y mediación, ya sea desde las instituciones públicas, ya sea desde entidades del tercer sector, como Cáritas ${ }^{7}$. Tales actores abogan por la negociación individual, envuelta en discreción, con las entidades bancarias. Se inclinan por recomendar a los deudores que acepten propuestas de refinanciación que permitan a las familias permanecer en la vivienda por el momento, con la esperanza de que su situación mejore cuando tengan que afrontar el aumento de las cuotas. Para ellos, la dación en pago, al implicar la pérdida de la vivienda, no es una solución deseable, como no lo es tampoco la estrategia de la confrontación pública con el banco con el objetivo de perjudicar su imagen.

En contraste con esto encontramos la postura de los activistas y co-participantes en movimientos sociales como la Plataforma de Afectados por la Hipoteca (PAH). Estos optan por la táctica de presionar a los bancos mediante movilizaciones, convocadas tanto en las agencias como en las oficinas centrales, exigiendo la dación en pago, la condonación de la deuda para los deudores ya desahuciados y la concesión de contratos de alquiler a precios asequibles.

Resulta evidente cómo estas dos aproximaciones difieren en términos políticos: las acciones colectivas tratan de fomentar -lográndolo en buena medidauna nueva conciencia del endeudamiento hipotecario como un problema estructural, revirtiendo la dinámica de culpabilización de los deudores que venimos describiendo, al tiempo que promueven procesos de "empoderamiento" (Colau y Alemany, 2012; Mangot, 2013; Mir García, França, Macías y Veciana, 2013; Sabaté, 2014). En contraste con esto, la mediación, individual y despolitizada, se orienta a la búsqueda de soluciones caso a caso.

En relación más estrecha con nuestra argumentación, la promoción activa de la decisión de dejar de pagar en las asambleas de la PAH puede interpretarse como un cuestionamiento de la norma social que impele a los deudores a devolver lo prestado (Graeber, 2011) y a cumplir con los contratos (Mauss, 1923/1979). En consecuencia, es esta postura más beligerante la que ha propiciado la legitimación de la propia condición de moroso hipotecario, su visibilización, así como la conversión de este colectivo en un actor social relevante en estos últimos años. Algo que se produce en el plano político, público, pero también 
a escala más micro y en el ámbito de la vida privada: en ambos sentidos la toma de conciencia acerca del carácter colectivo y estructural de la problemática ha frenado o revertido la auto-inculpación por parte de los deudores.

La etnografía revela también cómo, una vez tomada la decisión de dejar de pagar las cuotas hipotecarias, puede experimentarse una cierta liberación derivada del nuevo orden de prioridades de la economía doméstica. Juan narraba en estos términos una de sus conversaciones con el director de la oficina bancaria:

"Mira, te digo el orden: mis hijos, mi perro, mi gato... El último de la fila serás tú. Cuando ellos ya estén bien, tú estarás bien" (Juan).

El sobrendeudamiento hipotecario se re-evalúa, así, como un factor que no solo amenazaba la permanencia en la vivienda, sino que también desestabilizaba el sustento cotidiano en un doble sentido. Por un lado, ponía en peligro la satisfacción de otras necesidades, incluidas las más básicas (Lorenzo Gilsanz, 2014, p. 219), que pueden percibirse como más acuciantes teniendo en cuenta el marco temporal -de meses o años- en que se desarrollan los procesos de ejecución hipotecaria antes del desahucio. Lo vemos, por ejemplo, en la nueva preocupación de Esmeralda una vez asumida su incapacidad para cumplir con las cuotas:

“Cambió nuestra visión. Para mí ahora, aunque te parezca muy raro lo que te voy a decir, el problema no son los pisos, sino que el problema es comer cada día. A mí ahora ya me da igual que se los lleven [los dos pisos hipotecados] o no" (Emeralda).

Por otra parte, el sobreendeudamiento resultaba también una rémora que ejercía gran presión sobre los lazos de solidaridad entre parientes y amigos. Una presión que quizá pudo soportarse durante algún tiempo pero que finalmente se reveló como insostenible. En el caso de Maite, la imposibilidad de recabar apoyo para afrontar las cuotas fue pronto evidente:

\footnotetext{
"Hubo un mes que nos ayudaron mis padres. Otro mes los de mi marido. Pero piensa que eran cuotas de 1.000 euros y aquello iba para largo, mis padres no podían aguantar tantos meses. Dos meses te ayudan, pero iba para largo, no podrían aguantar" (Maite).
}

Un proceso muy similar es el que relata Esmeralda:

"Piensas: «al año que viene todo tiene que ir mejor» pero va a peor, todo lo contrario. Dices: «bueno, a ver si le pido este mes a mi padre que me ayude, el mes que viene a mis suegros, el siguiente a mi hermano»... Y se te hace una bola" (Esmeralda).
Es, pues, en estas circunstancias cuando la decisión de dejar de pagar la hipoteca deviene planteable y adquiere legitimidad en tanto que facilita el acceso a recursos básicos como, por ejemplo, la alimentación, y alivia las obligaciones acuciantes a las que en muchos casos estaba respondiendo el entorno social. Más en general, el abandono del empeño de pagar las cuotas zanja una situación insostenible que no llevaba a ninguna parte, unos esfuerzos que caían en saco roto y que solo posponían lo inevitable. En ese sentido es usual escuchar en las asambleas de la PAH la expresión "pan para hoy, hambre para mañana", cada vez que los participantes animan a un deudor a dar el paso en lugar de seguir con sus esfuerzos o aceptar una refinanciación. En palabras de Esmeralda:

"Nosotros se lo decimos aquí a la gente: "¿tú ves que dentro de un año vas a poder seguir pagando? ¿No? pues entonces deja de pagar ya». Porque luego los bancos dicen, paga 100 euros si puedes, como signo de buena voluntad. Nada de pagar, si no pagas la cuota entera eres moroso igualmente y no estás pagando más que los intereses. O ni eso" (Esmeralda).

Esta cita muestra cómo se les sugiere incluso que dejen pagar con cierta antelación, cuando ya se prevé que tarde o temprano se va a caer en el impago. Este consejo hace aún más visible la frontera moral que un deudor ha de cruzar para tomar tal decisión, venciendo una norma tan interiorizada como la que obliga a demostrar que se ha seguido pagando hasta el límite de lo posible o incluso más allá mediante nuevos endeudamientos, para poder seguir presentándose y auto-representándose como un deudor de buena fe.

En suma, la etnografía nos muestra cómo los esfuerzos hasta el momento dirigidos a continuar al corriente de pago se resignifican como contraproducentes para el mantenimiento del sustento, así como también para garantizar un mínimo de bienestar y de oportunidades de futuro para la familia, y muy especialmente para los hijos.

Pero, pese a la rotundidad y convicción con que se expresan muchos de los deudores que ya se encuentran en situación de impago, la decisión no está exenta de conflicto, debido a que el juicio acerca de la legitimidad del impago no necesariamente es compartido por todos los implicados. En ocasiones una decisión de este tipo, que constituye un evidente alivio económico, es objeto de crítica moral por parte del entorno familiar, aun cuando este esté simultáneamente apoyando a los deudores en lo material. En esos términos 
describe Vanessa al desacuerdo que mantiene con sus padres, quienes, por otra parte, han respondido al deber moral de dar cobijo a la familia:

"Es muy complicado. Ellos no lo asumen, no lo entienden. Eso lleva a un conflicto continuo en casa. Les cuesta. No lo entienden. Es su casa... su mentalidad es la herencia: "te dejo esto». Ellos cobran sus pensiones y con eso nos dan de comer" (Vanessa).

En el mismo sentido describe la inclinación de sus padres a priorizar sus obligaciones financieras por encima de cualquier otra consideración:

"Con los suministros... Mi padre es sagrado para eso. Estamos al día de todo. Por eso le cuesta entender lo de dejar de pagar hipoteca" (Vanessa).

Este desacuerdo básico en torno a la obligación de pagar la deuda desemboca en la proliferación de reproches y rencores, con el resultado de una erosión de las relaciones familiares (Laparra Navarro y Pérez Eransus, 2012, p. 23) que paradójicamente, en casos como el de Vanessa y su familia, ha de sobrellevarse en una situación de convivencia y hacinamiento.

Puede ocurrir también que los deudores sean de entrada reticentes a reconocer su situación de impago ante su entorno social. Así lo vivió Esmeralda durante los primeros tiempos:

"Al principio te da mucha vergüenza, sobre todo porque piensas que la gente te va a decir: «pues no haberte metido». Es una frase que mucha gente emplea. $Y$ luego ya después... pues la vergüenza se pasa y lo dices abiertamente. Pero al principio cuesta muchísimo porque, claro, te culpabilizas tú, y luego dices: «a ver, tampoco nadie pensaba que las cosas iban a ir así»" (Esmeralda).

El temor a la estigmatización o al conflicto puede llevar incluso a ocultar la situación durante un primer período, como es el caso de Vanessa de cara a su hermana:

"Ahora viene otra lucha bastante gorda, que es decírselo a mi hermana. Ella no lo sabe. Ya estuvo un tiempo sin hablar a mi padre porque me había avalado. Ahora cuando se entere de que he perdido su parte de herencia, que es lo único que le importa... Es otra guerra que viene ahora, que acabará con cualquier relación, creo. No lo entiende porque ella es otra de las que dicen que todo me ha pasado por mi culpa" (Vanessa).

Más allá de la reacción del entorno social más próximo, los deudores pueden verse también en la situación de tener recurrir a instituciones asistenciales, tanto estatales como del tercer sector. La decisión de acudir a estas entidades parece depender fuertemente del grado en que los afectados se auto-perciban como "necesitados" y estén dispuestos a asumir la posible estigmatización que el uso de estos recursos puede comportar, situándose públicamente en una condición de inferioridad de estatus, tal y como muestra la bibliografía antropológica sobre la reciprocidad y el don. En ocasiones, vemos cómo la existencia de apoyo familiar, por limitado que este sea, puede frenar la demanda de apoyo al Estado o a las entidades asistenciales. Así lo argumenta Maite:

"No nos ha hecho falta ir a los servicios sociales. Con la ayuda de la familia... Si fuéramos diciendo que él [el marido] solo cobra la ayuda y tal, probablemente sí que nos lo darían. Pero como tenemos a mi suegra que nos cocina cada día..." (Maite).

Frente a su situación, por la que se muestra agradecida hacia unos padres y suegros que ella misma caracteriza como "gente humilde", Maite describe cómo otra afectada por una ejecución hipotecaria, de origen migrante, tiene en la beneficencia su único recurso:

"Ella tiene tres [hijos] pequeñitos... así, escalonaditos. A ella todavía le hace más falta. Va a Cáritas a buscar comida y ropa. Nosotros no hemos tenido que ir a Cáritas" (Maite)

En el relato de Jenny aparece además la cuestión de la indignidad de esa vía de aprovisionamiento:

\footnotetext{
"Es que allí [en al banco de alimentos] la gente hasta se peleaba por la comida. Y mi hermana ya me dijo que no fuese, que ella me ayudaría, y más gente que me ha ayudado, mis jefes con la carne y demás... nos han ayudado mucho, en ese aspecto no nos podemos quejar" (Jenny).
}

Finalmente nos referiremos a la experiencia de la temporalidad que refieren los deudores en situación de impago. Común a todos sus relatos es la sensación de vivir al día, sin posibilidad de planificar siquiera a corto plazo, debido a la incertidumbre respecto a la estabilidad residencial y económica. A esa sensación alude Esteban cuando narra su día a día:

“Así como antes veías el futuro la mar de bien, de feliz... que ibas a lograr cosas... ahora no. Porque hay una barrera ahí. Lo único que puedes tener son ilusiones pero el futuro no lo controlas para nada. Vas viviendo el día a día y esperando. Estás viviendo solo 
el día a día, a ver qué pasa. Cuando te vas a dormir: «bueno, no ha pasado nada, nadie ha dicho nada, a ver mañana...»" (Esteban).

En tales circunstancias la planificación a más años vista queda completamente descartada, tal y como expresa Esmeralda:

"Con lo de comprar en Castellón, la idea era irnos allí [al jubilarnos] y vender el de aquí, quitarnos la hipoteca y tener un dinerito... o alquilar este y tener una renta para juntarla con la pensión, que entonces era una porquería... Y ahora ya ni te cuento, ya ni nos lo planteamos lo de la pensión. Es lo bueno, aprendes a no planificar porque ¿̇para qué?" (Esmeralda).

Esto no significa, no obstante, que los deudores no se esfuercen por tratar de mantener puertas abiertas hacia el futuro, muy especialmente el de la siguiente generación. En ese sentido descarta Esteban la posibilidad de que sus hijas abandonen los estudios para contribuir a la economía doméstica con un empleo a tiempo total:

"Los colegios hay que pagarlos. Por narices. Lo que no vamos a hacer es decirles a nuestras hijas que dejen de estudiar. Si el futuro ya está negro, intentan buscarse la vida, una carrera... No puedes decirles que no. Ellas ya lo hubiesen hecho, pero les hemos dicho que no". (Esteban).

\section{CONCLUSIÓN: MOROSIDAD Y RESPONSABILIDAD MORAL}

Testimonios como el de Esteban, junto con los de otras muchas personas que han contribuido a este estudio etnográfíco, nos permiten primeramente sostener que, si bien, en efecto, la decisión de dejar de pagar la hipoteca implica la transgresión de una norma social profundamente arraigada, tal decisión deviene en realidad la única opción posible cuando la deuda resulta insostenible e impide la satisfacción de necesidades básicas, la continuidad de la vida en condiciones dignas.

Pero aún podemos llevar el argumento un poco más allá. Sostenemos que la morosidad hipotecaria no debe ser interpretada, en la línea de ciertos discursos desacreditadores de los deudores y sus movilizaciones, como una falta de compromiso con la propia situación y con la de aquellos con quienes se han contraído obligaciones -ya sea mediante un contrato, como ocurre con los distintos proveedores y acreedores no hipotecarios, ya sea en términos morales, como ocurre con los hijos u otras personas dependientes. Por el contrario, cruzar la frontera del impago, con todas las dificultades, incertidumbres y sufrimientos implicados en ese paso, constituye una respuesta, a menudo la única posible, al deterioro de la economía doméstica causada por situaciones adversas como el desempleo, la disminución de los ingresos, los problemas de salud o las rupturas de pareja. Todo ello sitúa a los hogares en una situación de inseguridad en la tenencia de la vivienda que autores como Sales i Campos (Diagnosis 2013; Sales i Campos, 2014) identifican plenamente como una forma de exclusión residencial ${ }^{8}$.

Particularmente en el caso de los deudores hipotecarios, las graves dificultades experimentadas en el intento de adaptar las economías domésticas al entorno cambiante de la crisis financiera evidencian la rigidez de la estipulación de los términos de devolución (Guyer, 2012) y la violencia implicada en la obligación de pagar las deudas (Graeber, 2011). Los términos de devolución establecidos en los contratos de préstamo hipotecario, que de entrada legitiman la actitud implacable de los acreedores y el hecho de que estos puedan prescindir de toda consideración moral, se ven cuestionados por la realidad de los deudores. Estos, obligados a escoger entre "comer o pagar", reclaman la remoralización de la relación crediticia a la luz de su situación actual. Y en ocasiones denuncian además el carácter abusivo y fraudulento de unos préstamos que, ya de entrada, al dirigirse a sectores de población económicamente vulnerables y contemplar en consecuencia una alta probabilidad de impago, constituían desde un principio una perversión de las relaciones crediticias, dado que el acreedor no necesariamente aspiraba a que el crédito le fuera reembolsado (Gregory, 2012).

De hecho, los datos presentados ilustran cómo dejar de pagar las cuotas hipotecarias puede ser la única manera de seguir cumpliendo con el resto de responsabilidades que, aun en circunstancias económicas muy adversas, se consideran asumibles -por guardar proporción con los propios medios- o bien moralmente superiores -por responder a la inserción de los deudores en relaciones de reciprocidad. El deudor "de buena fe" se resignifica, así, como alguien que, pese a haber cejado en el empeño de seguir pagando las cuotas hipotecarias a toda costa, incumpliendo así con lo que de entrada se considera la principal obligación financiera de los grupos domésticos, mantiene una actitud comprometida con el mantenimiento de la vida y de la dignidad. 


\section{AGRADECIMIENTOS}

Esta investigación ha sido financiada parcialmente por la Wenner Gren Foundation for Anthropological Research (Post-PhD Grant 2014) y por la Generalitat de Catalunya (SGR 2014). La autora agradece a BalintÁbel Bereményi y a los participantes en el panel "la crisis hipotecaria en el Estado español: impactos y respuestas sociales", celebrado en el marco del I Congreso de la Asociación de Antropólogos Iberoamericanos en Red, las sugerencias para la mejora de las versiones anteriores del texto. También expresa su agradecimiento a todas las personas que se han prestado a colaborar con la investigación aportando sus experiencias.

\section{NOTAS}

[1] Según Laparra Navarro y Pérez Eransus (2012, p. 124), entre 2007 y 2010 se produjo un aumento significativo del número de hogares para los que el gasto en vivienda supone una carga elevada. De hecho, como muestra Ayala Cañón (2016, p. 152), el número de hogares sin ningún tipo de ingreso experimentó un aumento considerable durante los años de la crisis, entre 2007 y 2014.

[2] Esto se refiere a la doctrina rebus sic stantibus, según la cual un contrato puede llegar a declararse nulo ante una alteración sobrevenida de las circunstancias en las que fue firmado. Existe desacuerdo entre los jueces que hemos entrevistado acerca de su aplicabilidad en el caso hipotecario.

[3] Real Decreto-ley $1 / 2015$, de 27 de febrero, de mecanismo de segunda opor-

\section{BIBLIOGRAFÍA}

Ayala Cañon, L. (2016). El gasto público en programas de lucha contra la pobreza: tendencias, determinantes y necesidades de reforma. Papeles de Economía Española, 147, pp. 145-166.

Cabrera, P. J. (2004). La vida al ras. Educació Social. Revista d'intervenció socioeducativa, 27, pp. 11-20.

Cabrera Cabrera, P. J. (2009). La acción social con personas sin hogar en la España del siglo XXI. Avances y retos en la última década. En Laparra Navarro, M. y Pérez Eransus, B. (coords.). La exclusión social en España. Un espacio diverso y disperso en intensa transformación. Madrid: Fundación Foessa, pp. 173-219.

Carbonero Muñoz, D. y Ruiz Vega, A. (2016). Evolución en los procesos e itinerarios de las personas sin hogar en España: ¿Retorno al pasado? Empiria. Revista de Metodología de Ciencias Sociales, 34, pp. 39-78. https://doi.org/10.5944/ empiria.34.2016.16522 tunidad, reducción de carga financiera y otras medidas de orden social.

[4] Nótese el contraste entre esos ideales y los de los modelos de éxito social y económico que pretenden imponerse como hegemónicos, como los que provienen del mundo de las finanzas o de la cultura de Wall Street (Ho, 2009).

[5]. Esa fue la experiencia de Jenny cuando volvió a instalarse en casa tras el lanzamiento.

[6] Como, por ejemplo, el Real Decretoley $1 / 2015$.

[7] Cáritas ofrece un Servicio de Mediación en Vivienda, mientras que la Agència de l'Habitatge de la Generalitat de Catalunya ofrece un servicio de asesoramiento llamado Ofideute, y la Diputació de Barcelona ha creado una

Colau, A. y Alemany, A. (2012). Vides hipotecades. De la bombolla immobiliària al dret a l'habitatge. Barcelona: Angle Editorial.

Graeber, D. (2011). Debt. The first 5,000 years. New York: Melville House.

Gregory, C. A. (2012). On money debt and morality: some reflections on the contribution of economic anthropology. Social Anthropology, 20 (4), pp. 380396. https://doi.org/10.1111/j.14698676.2012.00225.x

Guyer, J. (2012). Obligation, binding, debt and responsibility: provocations about temporality from two new sources. Social Anthropology, 20 (4), pp. 491501. https://doi.org/10.1111/j.14698676.2012.00217.x

Ho, K. (2009). Liquidated. An Ethnography of Wall Street. Durham: Duke University Press. https://doi. org/10.1215/9780822391371 red de puntos de información llamada Servei d'Intermediació en Deutes de I'Habitatge, normalmente ubicados en las Oficinas de Vivienda de los ayuntamientos.

[8] En efecto, Sales (Diagnosis 2013, p. 13) identifica los retrasos en el pago de la hipoteca como factores estructurales -relacionados con procesos económicos o dinámicas del mercado inmobiliario- que pueden llevar al sinhogarismo en la medida en que la tenencia de la vivienda se torna insegura ante el riesgo de desahucio y en que los afectados por las ejecuciones pasan a vivir bajo un techo sin permiso legal, en situación de ocupación, o bien a hacerlo con amigos o familiares o en régimen de realquiler.

Laparra Mavarro, M. y Pérez Eransus, B. (coords.) (2012). Crisis y fractura social en Europa. Causas y efectos en España. Barcelona: Obra Social «La Caixa».

Lorenzo Gilsanz, F. (2014) (coord.) VII Informe sobre exclusión y desarrollo social en España. Madrid: Fundación Foessa.

Mangot, LI. (2013). La Plataforma de Afectados por la Hipoteca. De la crisis a la estafa. Del Prozac al empoderamiento. Clivatge. Estudis i testimonis sobre el conflicte i el canvi socials, 2, pp. 56-87. Disponible en http://revistes. ub.edu/index.php/clivatge/article/ view/10021/12890

Mauss, M. (1923/1979). Ensayo sobre los dones. Razón y forma del cambio en las sociedades primitivas. En: Mauss, M. Sociología y Antropología. Madrid: Tecnos, pp. 155-263.

Mir García, J., França, J., Macías, C. y Veciana, P. (2013). Fundamentos de la Pla- 
taforma de Afectados por la Hipoteca: activismo, asesoramiento colectivo y desobediencia civil no violenta. Educación Social. Revista de Intervención Socioeducativa, 55, pp. 52-61.

Moreno Márquez, G. y Aierdi Urraza, X. (2015). The impact of the crisis on homelessness in Spain: social intervention in a context of greater need and fewer resources. European Journal of Social Work, 19 (1), pp. 31-45. https://doi.org/ 10.1080/13691457.2015.1022712

Sabaté, I. (2014). Del país de los propietarios al país de los sobre-endeudados. Reciprocidad, solidaridad y proyectos de transformación sistémica en tiempos de crisis. Ars \& Humanitas, 8 (1), pp. 167-187. https://doi.org/10.4312/ ah.8.1.167-187

Sabaté, I. (2016a). The Spanish mortgage crisis and the re-emergence of moral economies in uncertain times. History and Anthropology, 27 (1), pp. 107-120. https://doi.org/10.1080/02757206.201 5.1111882

Sabaté, I. (2016b). Mortgage indebtedness and home repossessions as symptoms of the financialisation of housing provisioning in Spain. Critique of Anthropology, 36 (2), pp. 197-211. https://doi. org/10.1177/0308275X15614636

Sabaté, I. (2018). To repay or not to repay: financial vulnerability among mortgage debtors in Spain. Etnográfica, 22 (1), pp. 5-26. https://doi.org/10.4000/etnografica. 5130

Sales i Campos, A. (2014). Crisis, empobrecimiento y personas sin hogar. Dossier Catalunya Social, 34, pp. 3-31.

Scott, J. C. (1976). The Moral Economy of the Peasant. Rebellion and Subsistence in Southeast Asia. New Haven: Yale University Press.

Serrano de Nicolás, A. (2015). El control preventivo previo por notarios y registrado- res de la propiedad de las cláusulas de los préstamos hipotecarios. En: Izquierdo Blanco, P., Picó i Junoy, J. y Adán, F. (eds.). Manual de actuaciones frente a la ejecución hipotecaria inminente. El derecho de defensa del deudor hipotecario. Barcelona: Bosch, pp. 163-204.

Stout, N. (2015, 30 de marzo). Generating home (Theorizing the Contemporary Series). Cultural Anthropology [En línea]. Disponible en: http://www. culanth.org/fieldsights/655-generatinghome.

\section{Otros recursos}

Sales i Campos, A. Diagnosis 2013. Las personas sin hogar en la ciudad de Barcelona y la evolución de los recursos de la Red de Atención a Personas sin Hogar. Xarxa d'Atenció a Persones sense Llar, Barcelona. [En línea]. Disponible en http://www.bcn.cat/barcelonainclusiva/ca/2013/7/xarxa2_diagnosi2013_ es.pdf 